\title{
Justicia transicional y los límites de lo (posible) punible. Reflexiones sobre la legitimidad del proceso de paz en Colombia*
}

\author{
Recibido: 3 de octubre del 2018 • Aprobado: 21 de octubre del 2018 \\ https://doi.org/10.22395/ojum.v17n35al
}

Claudio Nash Rojas*

\begin{abstract}
RESUMEN
Este estudio propone que el proceso de paz colombiano ha ratificado que la justicia de transición encuentra límites en los derechos humanos en relación con tres aspectos: a) no son posibles las medidas de amnistía o indulto para violaciones graves de los derechos humanos; b) las medidas de impunidad solo son posibles si se cumplió con el deber de reparar a las víctimas; y c) las medidas penales que implican un tratamiento diferente de quienes incurrieron en violaciones de derechos humanos en el contexto del conflicto armado son posibles si el Estado proporciona ciertos derechos mínimos con respecto a la reparación de las víctimas. El Acuerdo de Paz del 2016 y la jurisprudencia del Tribunal Constitucional difieren de las normas elaboradas por la Corte Interamericana de Derechos Humanos sobre el deber de investigar y sancionar las violaciones de los derechos humanos.
\end{abstract}

Palabras clave: justicia transicional; derecho penal; proceso de paz.

Artículo de investigación. Facultad de Derecho, Universidad de Chile.

"* Licenciado en Ciencias Jurídicas de la Universidad de Chile y Doctor en Derecho de la misma universidad. Santiago, Chile. Profesor e investigador, Universidad de Chile, Santiago, Chile. Correo: cnash@derecho.uchile.cl Orcid: https://orcid. org/0000-0003-3124-166X 


\title{
Transitional Justice and the Limits of What is (possibly) Punishable. Reflections on the Legitimacy of the Peace Process in Colombia
}

\begin{abstract}
This study proposes that the Colombian peace process has ratified that transitional justice finds limits in human rights related to three aspects: a) amnesty or pardon measures for serious violations of human rights are not possible; b) measures of impunity are only possible if the duty of providing reparation to the victims was fulfilled; and c) penal or retributive measures that imply a different treatment for those who incurred in human rights violations in the context of the armed conflict are only possible if the State provides certain minimum rights in the victims' reparation. The 2016 Peace Agreement and the jurisprudence of the Colombian Constitutional Court differ from the norms elaborated by the Inter-American Court of Human Rights on the duty to investigate and sanction violations of human rights.
\end{abstract}

Keywords: transitional justice; criminal law; peace process.

\section{Justiça transicional e os limites do (possivel) punivel. Reflexões sobre a legitimidade do processos de paz na Colômbia}

\section{RESUMO}

Este estudo propõe que o processo de paz colombiano ratificou que a justiça de transição encontra limites nos direitos humanos com respeito a três aspectos: a) as medidas de anistia ou indulto não são possíveis para violações graves dos direitos humanos; b) as medidas de impunidade são possíveis apenas se o dever de reparar às vítimas foi cumprido, e c) as medidas penais que implicam um tratamento diferente de quem incorreu nas violações de direitos humanos no contexto do conflito armado são possíveis se o Estado proporcionar certos direitos mínimos referentes à reparação das vítimas. O Acordo de Paz de 2016 e a jurisprudência do Tribunal Constitucional diferem das normas elaboradas pela Corte Interamericana de Direitos Humanos sobre o dever de investigar e sancionar as violações dos direitos humanos.

Palavras-chave: justiça transicional; direito penal; processo de paz. 


\section{INTRODUCCIÓN}

Procesos de pacificación como el colombiano presentan desafíos teóricos y prácticos de gran complejidad. Uno de los aspectos que suponen mayor dificultad es equilibrar las necesidades propias de una negociación política en medio del conflicto armado y las consecuentes garantías que exigen las partes en conflicto para ponerle fin y, por otra parte, hacer que dichas garantías sean compatibles con las obligaciones internacionales asumidas por el Estado colombiano en materia de derechos humanos.

En el proceso de paz colombiano uno de los aspectos cruciales a resolver ha sido determinar cuál es el rol y el alcance de la respuesta penal frente a los crímenes cometidos en el marco del conflicto armado al cual se busca poner fin. Esta ha sido una de las preguntas clásicas de las experiencias de justicia transicional en la Latinoamérica: ¿cuánta impunidad requiere un proceso de justicia transicional para consolidar la democracia? En el caso de los procesos de pacificación la pregunta pasa a ser: ¿̇cuánta impunidad resiste la sociedad en conflicto para garantizar el proceso de paz?' Durante años, la tendencia parecía indicar que la paz sí se podía alcanzar a costa de la justicia, se les garantizaba por tanto la impunidad a los responsables de las hostilidades ${ }^{2}$.

Lo que hace interesante adentrarse en el complejo proceso de paz en Colombia

\footnotetext{
Sobre la pregunta para el caso colombiano, ver Teitel (2016; p. 287)

2 Un buen estudio sobre esta perspectiva se encuentra en Teitel (2000) y Barbosa (2016).
}

es que al negociar la paz con quienes potencialmente pueden ser perseguidos por graves casos de violaciones de derechos humanos, las medidas eficaces de pacificación -como son las amnistías e indultos- son parte de la discusión y simultáneamente, parte de los límites a dicha negociación3. El punto es que estas medidas, en principio no prohibidas expresamente por las normas del Derecho Internacional Humanitario, sí han encontrado un límite fuerte en el desarrollo del Derecho Internacional de los Derechos Humanos (DIDH), particularmente, en la experiencia del Sistema Interamericano de Derechos Humanos. Esta tensión ha obligado al replanteamiento de los alcances de los modelos de justicia transicional a nivel comparado, particularmente, en el componente de la justicia penal.

Como siempre ocurre en los procesos de justicia transicional (Zalaquett, 1999), el contexto es determinante para dar una respuesta clara de diseño normativo y encuadrar así las decisiones políticas adoptadas entre las partes en conflicto. Obviamente, no es lo mismo un proceso de transición una vez el conflicto ha terminado o se ha sustituido un régimen dictatorial que un proceso de pacificación con un conflicto en desarrollo (Uprimny, 2006; Comisión Interamericana de

\footnotetext{
A estos efectos, el Acuerdo de Paz sostiene: "En el ejercicio de dicha autonomía, aceptada y reconocida por el Derecho Internacional de los Derechos Humanos, el Estado puede apreciar y evaluar la complejidad, duración y gravedad del conflicto armado interno con el fin de diseñar y adoptar los mecanismos de justicia para lograr la paz dentro del respeto a los parámetros establecidos en el derecho internacional, en especial la garantía de los derechos humanos" (Oficina del Alto Comisionado para la Paz, OACP, 2016, p. 144).
} 
Derechos Humanos, CIDH, 2013; Knust, 2018). Este es un elemento que se debe considerar a la hora de dar una respuesta jurídica adecuada y pertinente para el conflicto en desarrollo.

La hipótesis que desarrolla el presente artículo es que el proceso de paz colombiano ha ratificado que la justicia transicional encuentra límites en el DIDH con relación a tres aspectos: a) no proceden amnistías o indultos respecto de graves violaciones de derechos humanos; b) sí son posibles medidas de impunidad condicionadas al deber de reparar a las víctimas; y c) sí proceden medidas penales que impliquen un trato diferenciado a quienes han incurrido en violaciones de derechos humanos en el ámbito del conflicto armado, siempre que se resguarden ciertos derechos mínimos con respecto a la reparación de las víctimas. De esta forma, se consolidaría la tesis de que los procesos de justicia transicional no abren espacios de excepcionalidad a las obligaciones internacionales sobre derechos humanos, sino que establecen condiciones particulares para su implementación.

El estudio se divide en las siguientes secciones: 1) los procesos de justicia transicional y el deber de investigar, perseguir y castigar a la luz de las obligaciones internacionales del Estado; 2) el rol de la política criminal en los procesos de justicia transicional; 3) el juicio de ponderación en el proceso de paz colombiano; 4) la legitimidad internacional del camino seguido por el proceso de paz en materia de justicia penal; 5) algunas conclusiones.

\section{LA OBLIGACIÓN DE JUZGAR Y SANCIONAR EN LOS PROCESOS DE JUSTICIA TRANSICIONAL EN LA EXPERIENCIA LATINOAMERICANA}

Los objetivos propios de todo proceso de transición en materia de derechos humanos son reparar los daños ocasionados a las víctimas de violaciones de derechos fundamentales y prevenir la repetición de estos hechos en el futuro (Oficina del Alto Comisionado para los Derechos Humanos, OACDH, 2009; Teitel, 2000). Los medios para obtener estos objetivos son el conocimiento de la verdad e impartir justicia, así como el diseño de una política de reparaciones a las víctimas de violaciones de derechos humanos ${ }^{4}$. Los instrumentos para lograr estos objetivos han sido variados, la verdad se ha buscado a través de mecanismos no jurisdiccionales, principalmente "comisiones de verdad" con distintas características; en el campo de la justicia, los esfuerzos se han centrado en nuestra región en la justicia punitiva; las reparaciones se han buscado a través de medidas tomadas desde políticas estatales (Boraine, 2000;

\footnotetext{
La Corte Constitucional señaló y analizó lo que significa la justicia transicional en C-577/2014 (sección 5.1); C-694/2015 /sección 4) y C-007/2018 (párrs. 113-129). En esta última sentencia señala: "La Corporación ha explicado el contenido de la justicia transicional como un conjunto amplio de procesos y mecanismos, judiciales y no judiciales, de carácter excepcional y transitorio, que responden a largos periodos de violencia generalizada, en los que se han cometido constantes violaciones de derechos humanos y al derecho internacional humanitario. Los propósitos de la justicia transicional son: (i) responder a la violencia generalizada y, por ende, asegurar el derecho a la paz; (ii) garantizar los derechos de las víctimas a la verdad, la justicia, la reparación y la no repetición de los hechos violentos; (iii) fortalecer al Estado de derecho y a la democracia; y (iv) promover la reconciliación social".
} 
Kritz, 1995; Hayner, 2010; Nash, 2010; Reyes, 2018; Neumann, 2018).

Frente a estos objetivos generales, la práctica comparada latinoamericana ha reconocido la existencia de otro elemento central en el diseño de una estrategia nacional en materia de transición a la democracia: la consolidación de un sistema democrático, esto es, dar viabilidad al sistema democrático formal y abrir espacios para su profundización (Zalaquett, 1999). En efecto, este objetivo general ha pasado a ser un criterio de corrección en los procesos democráticos ${ }^{5}$ y por tanto, ha servido para guiar y limitar las políticas públicas en materia de verdad y justicia (Tomuschat, 1999). Una variante de este principio general se encuentra en el caso del proceso de paz de Colombia, ya que en este, el criterio de corrección es la pacificación, esto es, lograr la paz luego de más de seis décadas de conflicto armado interno (Uprimny, 2006) .

Para entender la experiencia latinoamericana en materia de justicia transicional, cabe recordar la idea de Santiago Nino que estriba en que la realidad de los contextos políticos en la cual debieron tomarse las decisiones en materia de justicia punitiva, justificaba que no se

5 En este sentido, se sigue la idea de justicia procedimental imperfecta de Rawls (1971).

6 La cuestión de fondo es: si los procesos de justicia transicional han servido para resolver las cuestiones que surgen en casos de tránsito desde una sociedad autoritaria o en conflicto a una democrática (procesos verticales), ¿̇erán igualmente útiles para delinear procesos de transición en los cuales la discusión sobre los elementos de la justicia transicional pasan a ser parte del diseño de la terminación del conflicto (procesos horizontales)? (Orozco, 2009). cumpliera plenamente con las obligaciones internacionales, cuando esto pusiera en riesgo la continuidad del sistema democrático (Nino, 1991). Esta fue la base sobre la cual se construyó un modelo de justicia transicional en Argentina, Chile (Zalaquett, 1999), Sudáfrica (Boraine, 2000), entre otros (Sikkink, 2013), que contemplaba amplio conocimiento de la verdad, pero medidas restrictivas en materia de justicia (amnistías, indultos, prescripciones).

Sin embargo, la Corte Interamericana de Derechos Humanos (Corte Interamericana o Corte IDH), reconociendo las dificultades de los procesos nacionales, se distancia del modelo tradicional en materia de justicia transicional y sostiene que hay ciertos mínimos que el Estado está obligado a cumplir, por más difíciles que sean las circunstancias del país?

El argumento al que se recurre frecuentemente para sustentar una visión contraria a las legislaciones que limitan la actividad punitiva estatal, es que esta omisión constituye una violación al deber que tiene el Estado de garantizar el pleno goce y ejercicio de los derechos humanos, toda vez que al no investigar los sucesos y sancionar a los responsables, se consagra

\footnotetext{
Es así que le ha señalado a Colombia que: "[L]a Corte reconoce las difíciles circunstancias por las que atravesaba y atraviesa Colombia, en las que su población y sus instituciones hacen esfuerzos por alcanzar la paz. Sin embargo, las condiciones del país, sin importar qué tan difíciles sean, no liberan a un Estado Parte en la Convención Americana de sus obligaciones establecidas en ese tratado, que subsisten particularmente en casos como el presente" (Corte IDH. Caso de la Masacre de Pueblo Bello vs. Colombia. Sentencia del 31 de enero de 2006. Serie C No. 140, párr. 146).
} 
un estado de impunidad que envía un mensaje legitimador de las violaciones de derechos humanos y no previene de manera efectiva que se repitan en un futuro (Nash, 2009).

La obligación internacional de juzgamiento y sanción ante violaciones graves de derechos humanos no solo ha sido establecida en el sistema interamericano, sino también en otros foros internacio nales. En efecto, los principios de las Naciones Unidas sobre los derechos de las víctimas en materia de derechos humanos establecen concretamente el derecho que tienen las víctimas de violaciones a sus derechos humanos y al derecho internacional humanitario a que el Estado investigue y sancione a los responsables de violaciones de derechos humanos (Asamblea General de las Naciones Unidas, 2005). En este mismo sentido se pronunció el Comité de Derechos Humanos de Naciones Unidas (Comité Derechos Humanos, 1989: párr. 18).

De esta guisa, uno de los temas centrales en los procesos transicionales es precisamente el que plantea el Acuerdo de Paz de 2016 (OACP, 2016) en el sentido de establecer los límites a la obligación de juzgar y sancionar a los responsables de graves violaciones a los derechos hu manos en contextos transicionales complejos. Por ello, se analiza a continuación con mayor detención los fundamentos dados por la Corte Interamericana para establecer el límite a la decisión soberana de los Estados acerca de la forma en que pueden enfrentar sus procesos transicionales.
En el sistema interamericano la condena a las decisiones de los Estados que establecen límites al juzgamiento y sanción de las violaciones de derechos humanos se ha fundamentado en un "derecho a la verdad" que emana de las obligaciones generales del Estado de respeto y garantía de los derechos consagrados en la Convención Americana sobre Derechos Humanos $(\mathrm{CADH})^{8}$. En cuanto al deber de investigar, la Corte IDH ha determinado que esta es una obligación de medio que debe ser cumplida con toda seriedad por los Estados, de forma tal que se satisfagan ciertos requisitos mínimos necesarios para cumplir con la obligación de garantizar ${ }^{9}$. Al efecto, la Corte Interamericana ha señalado que la investigación debe ser efectiva y dirigida al juzgamiento y sanción de los responsables, proceso en el cual los representantes de las víctimas deben tener participación en todas las etapas e instancias y los resultados deben ser públicos ${ }^{10}$. Finalmente, ha consagrado la obligación de sancionar proporcional-

8 El derecho a la verdad ha sido desarrollado por la Corte Interamericana de Derechos Humanos (en adelante "la Corte") desde un doble punto de vista, como un derecho colectivo o social a conocer la verdad y como un derecho individual, ver: Corte IDH. Caso 19 Comerciantes vs. Colombia. Fondo, Reparaciones y Costas. Sentencia de 5 de julio de 2004. Serie C No. 109, párrs. 257-259. En el mismo sentido, para Colombia ver: Corte IDH. Caso de la Masacre de Pueblo Bello vs. Colombia. Sentencia de 31 de enero de 2006. Serie C No. 140, párr. 219; Caso de la Masacre de La Rochela vs. Colombia. Fondo, Reparaciones y Costas. Sentencia de 11 de mayo de 2007. Serie C No. 163, párr.147.

9 Esta ha sido jurisprudencia constante de la Corte Interamericana desde su primera sentencia contenciosa, ver Corte IDH. Caso Velásquez Rodríguez vs. Honduras. Fondo. Sentencia de 29 de julio de 1988. Serie C No. 4.

10 Corte IDH. Caso Masacre Plan de Sánchez vs. Guatemala. Reparaciones. Sentencia de 19 de noviembre de 2004. Serie C No. 116, párr. 98. 
mente a quienes hayan incurrido en estos ilícitos ${ }^{11}$. Este es el corpus interamericano en materia de juzgamiento y sanción de violaciones graves de derechos humanos.

Además, la Corte Interamericana se ha pronunciado sobre casos en que existe una investigación interna, pero esta no satisface garantías mínimas para las víctimas. En este supuesto se da lo que la Corte califica como "cosa juzgada fraudulenta" y que trae como consecuencia que en dicha situación no se extingue la responsabilidad del Estado en materia de justicia ${ }^{12}$. En este mismo sentido, un aspecto interesante para el caso colombiano es el relativo a la impunidad cuando ha habido una investigación, pero esta solo establece responsabilidades parciales. En estos casos, la Corte IDH ha

11 Al respecto, la Corte le señaló a Colombia en el 2007: "En cuanto al referido principio de proporcionalidad de la pena, la Corte estima oportuno resaltar que la respuesta que el Estado atribuye a la conducta ilícita del autor de la transgresión debe ser proporcional al bien jurídico afectado y a la culpabilidad con la que actuó el autor, por lo que se debe establecer en función de la diversa naturaleza y gravedad de los hechos. La pena debe ser el resultado de una sentencia emitida por autoridad judicial. Al momento de individualizar las sanciones se debe fundamentar los motivos por los cuales se fija la sanción correspondiente. En cuanto al principio de favorabilidad de una ley anterior debe procurarse su armonización con el principio de proporcionalidad, de manera que no se haga ilusoria la justicia penal. Todos los elementos que incidan en la efectividad de la pena deben responder a un objetivo claramente verificable y ser compatibles con la Convención (Corte IDH. Caso de la Masacre de La Rochela vs. Colombia. Fondo, Reparaciones y Costas. Sentencia de 11 de mayo de 2007. Serie C No. 163, párr. 196).

12 Al respecto, la Corte señaló: "El desarrollo de la legislación y de la jurisprudencia internacionales ha permitido el examen de la llamada "cosa juzgada fraudulenta" que resulta de un juicio en el que no se han respetado las reglas del debido proceso, o cuando los jueces no obraron con independencia e imparcialidad". (Corte IDH. Caso Carpio Nicolle y otros vs. Guatemala. Fondo, Reparaciones y Costas. Sentencia de 22 de noviembre de 2004. Serie C No. 117, párrs. 131). sido clara al señalar que la investigación debe ser completa (Corte IDH. Caso de la "Masacre de Mapiripán" vs. Colombia. Sentencia de 15 de septiembre de 2005. Serie C No. 134, párr. 296), que se debe determinar incluso la participación de los responsables intelectuales de los crímenes investigados; es decir que no basta la sola determinación de los autores materiales de los ilícitos graves que se investigan (Corte IDH. Caso 19 Comerciantes vs. Colombia. Fondo, Reparaciones y Costas. Sentencia de 5 de julio de 2004. Serie C No. 109, párr. 257). El fundamento del tribunal para dicha conclusión ha sido el derecho de los familiares de las víctimas y la sociedad en conjunto de conocer la verdad (derecho de acceso a la justicia basado en los arts. 8, 25.1 y 1.1 de la CADH) y con ello, evitar que estos hechos vuelvan a suceder (garantía de no repetición) $)^{13}$.

Luego de haber establecido el alcance de la obligación de juzgar y sancionar, resulta pertinente analizar las posibles excepciones. La Corte Interamericana ha sostenido constantemente que los Estados deben evitar tomar medidas internas que limiten esta obligación frente a "crímenes graves", entendiendo por tales las desapariciones forzadas, ejecuciones extrajudiciales y torturas sistemáticas ${ }^{14}$. Esta delimitación

13 A modo de ejemplos ver: Corte IDH. Caso 19 Comerciantes vs. Colombia. Fondo, Reparaciones y Costas. Sentencia de 5 de julio de 2004. Serie C No. 109, párr. 259; Caso Rodríguez Vera y otros (Desaparecidos del Palacio de Justicia) vs. Colombia. Excepciones Preliminares, Fondo, Reparaciones y Costas. Sentencia de 14 de noviembre de 2014. Serie C No. 287.

14 La distinción la explica la Corte con detalle en: Corte IDH. Caso Goiburú y otros vs. Paraguay. Fondo, Reparaciones y Costas. Sentencia de 22 de septiembre de 2006. Serie C No. 153, párr. 88. 
es clarificadora, ya que identifica los casos en que se pueden adoptar este tipo de medidas legítimamente y en cuáles no. En efecto, para la Corte IDH, cuando se está ante infracciones "graves", no procede implementar medidas que limiten la investigación y condena (amnistías, prescripciones e indultos) (Corte IDH. Caso 19 Comerciantes vs. Colombia. Fondo, Reparaciones y Costas. Sentencia de 5 de julio de 2004. Serie C No. 109, párr. 262; Caso de la "Masacre de Mapiripán" vs. Colombia. Sentencia de 15 de septiembre de 2005. Serie C No. 134, párr.304; Caso de la Masacre de La Rochela vs. Colombia. Fondo, Reparaciones y Costas. Sentencia de 11 de mayo de 2007. Serie C No. 163, párr. 294); en los otros casos de violaciones de derechos humanos que no correspondan a este núcleo, las medidas se considerarían legítimas (Corte IDH. Caso Vera Vera y otra vs. Ecuador. Excepción Preliminar, Fondo, Reparaciones y Costas. Sentencia de 19 de mayo de 2011. Serie C No. 226, párr. 118).

El efecto de fundar en las obligaciones convencionales de los Estados la restricción a la discrecionalidad estatal sobre la pertinencia o no de utilizar el instrumento penal, es que dicha decisión deja de ser una mera liberalidad del Estado (Corte IDH. Caso Gomes Lund y otros ("Guerrilha do Araguaia") vs. Brasil. Excepciones Preliminares, Fondo, Reparaciones y Costas. Sentencia de 24 de noviembre de 2010. Serie C No. 219, párr. 175). Lo anterior trae consecuencias relevantes para la discusión que plantea el caso colombiano, ya que establecer límites a esta obligación estatal tiene que responder a un estándar de escrutinio tanto nacional como internacional.

El caso más polémico para la Corte IDH en esta línea de establecer restricciones a las amnistías fue el Caso Gelman vs. Uruguay, relativo a una ley de amnistía ratificada en una democracia a través de dos plebiscitos. En este caso, la Corte IDH señaló que existen límites, incluso para lo que se puede decidir en procesos democráticos (Caso Gelman vs. Uruguay. Fondo y Reparaciones. Sentencia de 24 de febrero de 2011. Serie C No. 221, párr. 238) en relación con la obligación de investigar y sancionar, basado en el derecho de las víctimas a ser reparadas (Caso Gelman Vs. Uruguay. Fondo y Reparaciones. Sentencia de 24 de febrero de 2011. Serie C No. 221, párr. 229).

Parece pertinente recalcar que estas medidas que obligan al Estado a investigar y sancionar y establecen límites a las excepciones, a juicio de la Corte Interamericana y de otros órganos de derechos humanos, hacen parte de procesos de reparación en el sentido más amplio del término, esto es, medidas a las que está obligado el Estado como consecuencia de la responsabilidad internacional que surge por no proteger a las personas sujetas a su jurisdicción en el marco del conflicto armado (Comisión de Derechos Humanos, 2000; Asamblea General Naciones Unidas (AG/ONU), 2005; de Greiff, 2006, Nash, 2009). Para la Corte IDH, las medidas de actuación en el ámbito interno son 
parte de las medidas de garantía de no repetición (Nash, 2013) ${ }^{15}$.

Las preguntas que surgen, en consecuencia, son: ¿cuál es el mejor camino para alcanzar estos fines?, ¿es el instrumento penal un medio idóneo?, ¿es el instrumento penal un medio ineludible?

\section{EL ROL DE LA PERSECUCIÓN CRIMINAL EN EL MARCO DE UN PROCESO DE PACIFICACIÓN}

Para dar respuesta a las preguntas anotadas es necesario entrar al tema de fondo: el rol de la respuesta penal en los procesos de justicia transicional. Todo el desarrollo argumentativo revisado le ha permitido a la Corte Interamericana concluir que el fundamento de las obligaciones del Estado en el campo de la obligación de juzgar y sancionar es evitar la impunidad y así garantizar la no repetición ${ }^{16}$. En efecto, según el razonamiento de la Corte IDH, en aquellos casos en que el Estado no cumpla con las obligaciones de juzgamiento y sanción a las que se ha hecho referencia, se estaría en una situación de impunidad que viola la obligación de garantía que pesa sobre los Estados para con los individuos sujetos a su jurisdicción (Corte IDH. Caso de la "Panel Blanca" (Paniagua Morales y otros) vs. Guatemala. Fondo.

15 En este mismo sentido se había pronunciado la Corte Constitucional colombiana en C-694/2015, que establece que la obligación de sancionar a los responsables deriva de los arts. 1.1 y 2 de la CADH, cuyos objetivos son la igualdad, prevención integral, educación y difusión, denuncia, prevención, erradicación de factores de riesgo y prevención específica y en los casos de crímenes contra la humanidad.

16 Una visión crítica sobre esta perspectiva frente a la pena por parte de la Corte Interamericana se puede encontrar en Mañalich (2010).
Sentencia de 8 de marzo de 1998. Serie C No. 37, párr. 173). Incluso, la Corte ha señalado que la falta de respuesta por parte del Estado puede provocar una situación de "impunidad crónica" (Corte IDH. Caso Masacre Plan de Sánchez vs. Guatemala. Reparaciones. Sentencia de 19 de noviembre de 2004. Serie C No. 116, párr. 95) incompatible con las obligaciones convencionales de los Estados.

Por ello, la cuestión es si las investigaciones y la sanción a los responsables se debe enmarcar en un proceso penal en el cual se juzgue a los responsables y la sociedad en su conjunto pueda conocer la verdad judicialmente establecida con respecto a los hechos acaecidos, o bien, si los procesos de justicia transicional están pensados, precisamente, para limitar esta obligación y se abren a otras posibilidades (Reyes, 2018). Un ejemplo relevante de esta cuestión es la tesis que propone un estudio, previo a los Acuerdos de Paz de 2016, elaborado por Rodrigo Uprimny y Camilo Sánchez (Uprimny y Sanchez, 2019), en este los autores se preguntaban si la respuesta penal es la única alternativa posible para alcanzar los objetivos de pacificación. El punto de partida para estos autores es un informe del relator de Naciones Unidas en el tema transicional, el también colombiano Pablo de Greiff, en el sentido de que la respuesta penal, en el marco de los procesos de justicia transicional, debería cumplir con los siguientes objetivos: i) reconocer a las víctimas; ii) restablecer la confianza entre las personas y, particularmente, de estas con respecto a las instituciones estatales; iii) consolidar el Estado de derecho; y, iv) 
promover la cohesión social o reconciliación (Consejo de Derechos Humanos de Naciones Unidas (2014a, párr. 99).

En dicho contexto, Uprimny y Sánchez (2019) plantean que es necesario que cada sociedad defina si la aplicación del instrumento penal contribuye o no a dichos objetivos, dependiendo de los intereses, contexto y mecanismos de su transición, sin que se sobredimensione el rol de la persecución penal en el proceso (Uprimny y Sánchez, 2019).

La experiencia latinoamericana es muy relevante para determinar si esta tesis es o no sostenible. La respuesta apunta en un sentido negativo, esto es, cuando no ha habido una respuesta penal satisfactoria, lo único que han conseguido los Estados es mantener vigente el tema de la transición durante décadas (Teitel, 2000; Bulygin, 2001). La experiencia sudafricana, por su parte, ha demostrado que no usar el instrumento penal, no resolvió el tema de la impunidad ${ }^{17}$. En el caso español se puede identificar que décadas después de la transición, la sociedad española retoma el tema de la justicia como una cuestión de debate público, político y judicial, a partir de un modelo basado en la impunidad (Consejo de Derechos Humanos de Naciones Unidas, 2014b).

Pareciera que un elemento adicional que se ha de tener en consideración es que la respuesta penal se considera como una respuesta culturalmente pertinente en

17 Howard Varney (2013), investigador del International Center for Transitional Justice (ICTJ), ofrece un interesante análisis al respecto la región latinoamericana. A diferencia de otros sistemas jurídicos comparados, en los cuales la justicia penal tiene un rol menor en la solución de conflictos (las experiencias africana y asiática son relevantes en esta línea) ${ }^{18}$, en nuestros sistemas jurídico-culturales, la respuesta penal sí es relevante como juicio de reproche y como procedimiento confiable de sanción ${ }^{19}$. Aún en un sentido de derecho penal mínimo, en que se eviten excesos como el populismo punitivo, la respuesta penal para la protección de valores centrales de la sociedad -como son los propios derechos humanos- es una respuesta legítima. A continuación, algunos ejemplos que avalan esta apreciación.

La Corte Interamericana señaló sobre la respuesta penal en el caso Kimel vs. Argentina (Corte IDH. Caso Kimel vs. Argentina. Fondo, Reparaciones y Costas. Sentencia de 2 de mayo de 2008 Serie C No. 177) que esta es legítima y que "en una sociedad democrática el poder punitivo sólo [sic] [...] se ejerce en la medida estrictamente necesaria para proteger los bienes jurídicos fundamentales de los ataques más graves que los dañen o pongan en peligro [...]" (Corte IDH. Caso Kimel vs. Argentina, párr. 76) y que "el empleo de la vía penal debe corresponder a la necesidad de tutelar bienes jurídicos fundamentales frente a conductas que impliquen graves lesiones a dichos bienes,

18 Un buen resumen del caso de Ruanda, aplicado a la experiencia colombiana se encuentra en Knust (2018).

19 Sobre este particular, resulta muy diciente el rechazo al Acuerdo de Paz en el plebiscito de octubre de 2016 en el cual triunfó la opción del "no" con el 50,2\% y cuya campaña se había basado en la idea de que era un pacto de impunidad (Miranda, 2016) 
y guarden relación con la magnitud del daño inferido" (Corte IDH. Caso Kimel vs. Argentina, párr. 77).

Como juicio de reproche simbólico ${ }^{20}$, es claro que con respecto a aquellas conductas más graves, la respuesta penal aparece como una opción de última ratio, pero sin dejar de ser una opción legítima ${ }^{21}$. Este es un acuerdo ampliamente aceptado a nivel internacional, como lo demuestra el consenso mundial que representa el Estatuto de Roma $(1998)^{22}$ en cuyo preámbulo "[recuerda] que es deber de todo Estado ejercer su jurisdicción penal contra los responsables de crímenes internacionales"23. Más recientemente, los trabajos de la Comisión de Derecho Internacional sobre Crímenes de Lesa Humanidad se encaminan en el mismo sentido. En su propuesta de preámbulo (2017) señaló que "puesto que

20 Sobre el uso del instrumento penal en la teoría general y en su aplicación al caso colombiano, ver Knust, 2018.

21 Una perspectiva interesante sobre el rol de la pena como acción comunicativa la ofrece Mañalich (2010, pp. 76-88).

22 El texto del Estatuto de Roma se distribuyo 7 como documento A/CONF.183/9, del 17 de julio de 1998, enmendado por los procès- verbaux de 10 de noviembre de 1998, 12 de julio de 1999, 30 de noviembre de 1999, 8 de mayo de 2000, 17 de enero de 2001 y 16 de enero de 2002 , entró en vigor el $1^{\circ}$ de julio del 2002. A septiembre del 2018, cuenta con 133 Estados parte, 28 de los cuales son latinoamericanos y del Caribe.

23 "Afirmando que los crímenes más graves de trascendencia para la comunidad internacional en su conjunto no deben quedar sin castigo y que, a tal fin, hay que adoptar medidas en el plano nacional e intensificar la cooperación internacional para asegurar que sean efectivamente sometidos a la acción de la justicia // Decididos a poner fin a la impunidad de los autores de esos crímenes y a contribuir asi[ a la prevención de nuevos crímenes // Recordando que es deber de todo Estado ejercer su jurisdicción penal contra los responsables de crímenes internacionales" (Corte Penal Internacional, 1998, Preámbulo). los crímenes de lesa humanidad no han de quedar impunes, ha de asegurarse el enjuiciamiento efectivo de esos crímenes mediante la adopción de medidas a escala nacional y el fomento de la cooperación internacional [...]" (Comisión de Derecho Internacional, 2017).

Ahora, desde un punto de vista, ya no sustantivo sino procedimental, la verdad obtenida a través de un procedimiento penal es una respuesta apropiada (Corte IDH. Caso Almonacid Arellano y otros vs. Chile. Excepciones Preliminares, Fondo, Reparaciones y Costas. Sentencia de 26 de septiembre de 2006. Serie C No. 154, párr. 150). En el caso del conocimiento de la verdad - uno de los objetivos propios de los procesos transicionales - la verdad no es resultado solo de procedimientos administrativos - comisiones de verdad (Hayner, 2010)-, la verdad procesal penal cobra un papel ineludible ${ }^{24}$.

En definitiva, no es posible para el Estado colombiano descartar la respuesta penal en los casos de graves violaciones de derechos humanos y, por tanto, lo que queda es determinar si dicha respuesta puede ser objeto de ciertos matices en casos de violencia extraordinaria, en los cuales el derecho penal no ha sido pensado como respuesta estructural sino individual (Reyes, 2018). El aspecto a resolver es si hay otros derechos en juego que puedan matizar la respuesta "ideal" (juzgamiento y sanción de todas las violaciones de derechos humanos en el marco del conflicto armado) en pos de

\footnotetext{
24 La Corte Constitucional colombiana se ha pronunciado
} en este sentido, ver C-694/2015, sección 4.6. 
darle viabilidad al proceso de pacificación con el que la sociedad colombiana está comprometida.

\section{EL JUICIO DE PONDERACIÓN COMO RESPUESTA A LA TENSIÓN ENTRE LA OBLIGACIÓN DE JUZGAR Y SANCIONAR PENALMENTE Y LA VIABILIDAD DEL PROCESO DE PACIFICACIÓN}

Una opción para el proceso de pacificación, que es la base sobre la cual se construyó el Acuerdo de Paz de 2016, es aceptar que existe un deber de investigar, sancionar y reparar como medida de reparación, pero que a la vez, existe una obligación del Estado colombiano de avanzar en un proceso de paz que satisfaga un derecho constitucionalmente para garantizar la paz ${ }^{25}$.

En el caso colombiano hay dos principios en colisión: por un lado se encuentra la obligación de juzgar y sancionar a los responsables de graves violaciones de derechos humanos y por el otro, la necesidad de adoptar medidas eficaces (trato diferenciado) para viabilizar el acuerdo de paz ${ }^{26}$. Este conflicto se podría resolver de una manera simple: al colisionar un derecho humano con un interés social difuso, el interés debería doblegarse ante el derecho ya que estos

25 Un análisis explícito en este sentido se encuentra en la reciente sentencia de la Corte Constitucional C-007/2018 en la cual señala que "Bajo el marco normativo vinculante $y$, se insiste, en un momento de transición, el deber de investigar, juzgar y sancionar y los derechos de las víctimas sufren tensiones con facetas de otros principios y derechos constitucionales, que deben ser debidamente ponderadas con miras a lograr una paz estable y duradera" (párr. 392).

26 Esta perspectiva es la que ha seguido la Corte Constitucional, ver C-007/2018, bloque temático B.6. representan la base del acuerdo político y, en consecuencia, los derechos fundamentales son limitantes para estos intereses. Empero, en transiciones de un conflicto armado a la paz, este camino no parece resolver el problema ya que inviabiliza el proceso. Así las cosas, surgen dos líneas de argumentación. La primera se basa en la relativización del hecho de que exista una obligación internacional de dar una respuesta penal frente a violaciones graves de derechos humanos ${ }^{27}$; la segunda consiste en argumentar que en el caso de Colombia, la paz es un derecho reconocido constitucionalmente (art. $22^{28}$ ) y que este se debe ponderar para resolver la tensión debido a la obligación de juzgar y sancionar.

La segunda alternativa parece ser coherente con el sistema de derechos humanos y es la que adoptó la Corte Constitucional ${ }^{29}$. En efecto, para resolver dicho conflicto es necesario hacer un ejercicio de ponderación siguiendo algunos pasos: en primer lugar, evaluar el nivel de afectación de un principio para lograr la efectividad del que se le opone; en segundo lugar, elegir aquella medida

27 Este era el camino que plantean autores como Uprimny y Sanchez (2019), el costo de la paz era graduar el acuerdo sobre la obligatoriedad de juzgar graves violaciones de derechos humanos; así, la justicia transicional era considerado el espacio para legitimar la impunidad en el sentido de Nino (1991), en el marco de la transición argentina y de Zalaquett (1999), en el caso chileno.

28 El artículo 22 de la Constitucuión colombiana dispone: "La paz es un derecho y un deber de obligatorio cumplimiento".

29 La sentencia C-007/2018 es la mejor muestra de esta apuesta por la ponderación como método para legitimar las medidas relacionadas con la justicia en el Acuerdo de Paz. Se aconseja ver en particular, los párrs. 95-106 de dicha sentencia. 
que de menor manera afecte el principio que se va a sacrificar en beneficio del otro; finalmente, en caso de que no sea posible lograr dicho objetivo, se deben entregar las razones suficientes para justificar la decisión tomada (Alexy, 2002).

Si se asume que este es un conflicto entre dos principios de igual jerarquía, tal como lo sostiene la Corte Constitucional, y se sigue el esquema de armonización constitucional (Prieto Sanchís, 2003), habría que evaluar que el trato diferenciado (amnistías, justicia especial para la paz) constituye una medida que, en el caso concreto, permite viabilizar un principio (pacificación) que se considera altamente valorable y, por tanto, que será necesario sacrificar el otro principio en juego (plena investigación y sanción penal), ya que su matización parece necesaria y conducente para el logro de la paz ${ }^{30}$. En efecto, si estamos ante un conflicto entre principios de igual jerarquía, tesis razonable para el caso colombiano, la armonización se debe hacer sobre la base de "niveles" de afectación (leve, medio y grave) para determinar la proporcionalidad de las medidas y no haciendo que prevalezca un principio sobre otro de manera absoluta (Prieto Sanchís, 2003). Según Alexy, las afectaciones graves pueden ser de tres

30 "Finalmente, las cesiones que el Estado haga en materia de su deber de investigar, juzgar y sancionar no pueden ser incondicionadas, por lo tanto, solo serán válidas constitucionalmente en tanto aporten de manera relevante a la superación del conflicto, a la consecución de una paz estable y duradera, y en la medida en que potencialicen los derechos de todas las víctimas del conflicto, y de la sociedad en general, especialmente en materia de verdad, reparación y no repetición" C-007/2018, párr. 396. niveles: graves, bastante graves y extraordinariamente graves (Alexy, 2005, p. 70).

Si se está ante un derecho constitucional (paz) altamente valorable, se justifican medidas que afecten el derecho a investigar y sancionar en forma grave, siempre y cuando resulten sean necesarias para viabilizar el proceso de paz. Si se analiza el Acuerdo de Paz colombiano bajo esta lógica, se resuelve el tema de la siguiente forma: a) las amnistías totales de los crímenes graves cometidos por la jefatura del bando que ha luchado contra el Estado, al ser una medida que afecta el derecho opuesto en forma extraordinariamente grave -que llega a anularlo-, se descartan, aunque se establecen sanciones disminuidas ${ }^{31}$; b) las amnistías condicionadas, pero con sanción penal disminuida ${ }^{32}$ para crímenes políticos y conexos cometidos en el marco del conflicto armado ${ }^{33}$ constituiría una afectación grave a la obligación de

31 El Acuerdo de Paz excluye estos ilícitos del ámbito material de las amnistías en los siguientes términos "40. No serán objeto de amnistía ni indulto ni de beneficios equivalentes los delitos de lesa humanidad, el genocidio, los graves crímenes de guerra -esto es, toda infracción del Derecho Internacional Humanitario cometida de forma sistema $\square$ tica -, la toma de rehenes u otra privación grave de la libertad, la tortura, las ejecuciones extrajudiciales, la desaparición forzada, el acceso carnal violento y otras formas de violencia sexual, la sustracción de menores, el desplazamiento forzado, además del reclutamiento de menores, todo ello conforme a lo establecido en el Estatuto de Roma".

32 El modelo final del acuerdo de paz descartó formas de amnistía sin sanción penal, como algunos proponían (Uprimny y Sánchez, 2019).

33 Señala en el N. ${ }^{\circ} 38$ que, "Conforme a la anterior disposición [Protocolo II Convenios de Ginebra], se amnistiarán e indultarán los delitos políticos y conexos cometidos en el desarrollo de la rebelión por las personas que formen parte de los grupos rebeldes con los cuales se firme un acuerdo de paz". 
juzgar y sancionar (puesto que la pena no es proporcional) pero sería razonable en relación con el objetivo de pacificación (no impide conocer la verdad, reparar a las víctimas y dar garantías de no repetición); y finalmente c), establecer una forma de trato diferenciado para la administración de justicia, ya que los casos de los miembros de las FARC y funcionarios policiales que hayan cometido delitos no calificados como graves en el marco del conflicto armado serán juzgados por el sistema creado ad hoc de Justicia Especial para la Paz - aunque respecto de los funcionarios estatales su concurrencia será voluntaria y no obligatoria-, todo ello con la finalidad de alcanzar los objetivos de verdad, reparación y garantía de no repetición de las víctimas ${ }^{34}$. Este es el marco de legitimidad de los Acuerdos de Paz de 2016 que persigue viabilizar el juicio de ponderación y adecuar las soluciones dentro del esquema constitucional e internacional que compromete al Estado colombiano ${ }^{35}$.

34 El Acuerdo de Paz dispone que: "El componente de Justicia también se aplicará respecto de los agentes del Estado que hubieren cometido delitos relacionados con el conflicto armado y con ocasión de éste [sic], aplicación que se hara $\square$ de forma diferenciada, otorgando un tratamiento equitativo, equilibrado, simultáneo y simétrico. En dicho tratamiento debera $\square$ tenerse en cuenta la calidad de garante de derechos por parte del Estado" (N. ${ }^{\circ}$ 32).

35 El Acuerdo de Paz establece que: "La Jurisdicción Especial para la Paz (JEP), es una jurisdicción especial que ejerce funciones judiciales de manera autónoma y preferente sobre los asuntos de su competencia, en especial respecto a conductas consideradas graves infracciones al Derecho Internacional Humanitario o graves violaciones de los Derechos Humanos. Entrara[ en vigor en los términos establecidos en el Acuerdo Final. Se aplicará únicamente a conductas cometidas con anterioridad a su entrada en vigor" (N. $\left.{ }^{\circ} 13\right)$. Un completo análisis al respecto se encuentra en Corte Constitucional, C-007/2018, relativa a la Ley 1820/2016
Lo que queda por analizar es si este esquema de pacificación pasa la prueba de legitimidad de acuerdo con los estándares internacionales de derechos humanos.

\section{EN BUSCA DE UNA SALIDA COHERENTE PARA EL TEMA DE LAS AMNISTÍAS Y TRATOS JUDICIALES DIFERENCIADOS EN RELACIÓN CON EL PRINCIPIO DE REPARACIÓN INTEGRAL}

Como se ha expuesto, el Acuerdo de Paz se basa en el trato diferenciado (amnistías, procedimientos de justicia especial para la paz) con respecto a los responsables de violaciones de derechos humanos cometidas en el marco del conflicto armado colombiano; no se está hablando de una obligación "maximalista" en la cual se exija el juicio y castigo de todos los criminales y con respecto a todos los crímenes cometidos durante el conflicto ${ }^{36}$. En este sentido, es posible pensar en medidas de perdón que viabilicen el proceso de paz, en el entendido de que este perdón se asocia a compromisos con las víctimas y sus derechos ${ }^{37}$, en particular, su derecho a la verdad, la reparación y las garantías de no repetición ${ }^{38}$.

sobre aministías. Esta ley se dictó en base al Acto Legislativo 01 de 2016.

36 La idea de exigencias "maximalistas" está en la base de la crítica realizada por Uprimny y Sánchez (2019) a los estándares interamericanos en materia de juzgamiento y sanción de graves violaciones de derechos humanos.

37 La Corte Constitucional ha señalado que la reparación es "un límite infranqueable para el legislador y el gobierno dentro de un marco de justicia transicional" (C-694/2015, sección 5.4, p. 167).

38 La Corte Constitucional ha sido clara en el sentido de que estos elementos constituyen los mínimos que legitiman el proceso de paz basado en los derechos de las víctimas. Ver C-694/2015, sección 4.4 en la que se identifican estos como requisitos ineludibles para el establecimiento de un trato más benigno a responsables 
En este punto cobra todo su valor la distinción de Orozco (2009) en el sentido de que las transiciones de conflictos armados corresponden a actos de barbarie simétricas u horizontales que son distintas a las verticales en las cuales las violaciones provienen del Estado. En efecto, en una transición en el marco de un proceso de pacificación, no se enfrenta una discusión sobre el auto-perdón del Estado por sus propios crímenes, estas medidas estarían absolutamente prohibidas (Corte IDH. Caso Barrios Altos vs. Peru[. Fondo. Sentencia de 14 de marzo de 2001. Serie C No. 75, párrs. 41-43). En los procesos de pacificación el marco normativo es diferente, ya que medidas de perdón con respecto a terceros beligerantes sí son posibles. Así lo establece el Protocolo II adicional a los Convenios de Ginebra de 1949, relativo a la protección de las víctimas de los conflictos armados sin carácter internacional (1977), en el sentido que:

\begin{abstract}
Art. 6.5: A la cesación de las hostilidades, las autoridades en el poder procurarán conceder la amnistía más amplia posible a las personas que hayan tomado parte en el conflicto armado o
\end{abstract}

de violaciones no graves de derechos humanos que permitan investigar a fondo los hechos, restablecer derechos mínimos a la verdad y reparación, y diseñar medidas de no repetición; y en C-694/2015 punto 5.6 en la cual se señala explícitamente que "la verdad y la justicia, [...], al lado de la reparación, componen una triada inescindible" para garantizar los derechos de las víctimas. Todo el análisis de la C-007/2018 se hace sobre la base de estos elementos para ver la legitimidad de las medidas especiales en materia de justicia. Una mirada al rol de las víctimas en los procesos de reparación enmarcados en procesos de justicia transicional y la necesidad de participación se encuentra en Robins (2017). que se encuentren privadas de libertad, internadas o detenidas por motivos relacionados con el conflicto armado.

La propia Corte Interamericana, en el caso El Mozote vs. El Salvador (2012), señaló:

\begin{abstract}
[...] puede entenderse que el artículo 6.5 del Protocolo II adicional está referido a amnistías amplias respecto de quienes hayan participado en el conflicto armado no internacional o se encuentren privados de libertad por razones relacionadas con el conflicto armado, siempre que no se trate de hechos que, como los del presente caso, cabrían en la categoría de crímenes de guerra e, incluso, en la de crímenes contra la humanidad. (Corte IDH. Caso Masacres de El Mozote y lugares aledaños vs. El Salvador. Fondo, Reparaciones y Costas. Sentencia de 25 de octubre de 2012. Serie C No. 252, párr. 286)
\end{abstract}

Cabe analizar cada una de las situaciones planteadas en el Acuerdo de Paz de 2016².

39 En esta materia, tuvo gran impacto en el proceso colombiano, e incluso el Acuerdo de Paz cita el hecho de que un grupo de jueces se unió al fallo razonado por el juez García Sayán (OACP, 2016, sección 5.1.2.), cuando señala que "El hecho es que en el contexto específico de procesos de violencia generalizada y de conflictos armados no internacionales el recurso de la amnistía puede conducir, al menos teóricamente y según los casos o circunstancias específicas, a rumbos en diversas direcciones [...] que plantean, en consecuencia, un abanico de posibles resultados que pueden fijar los márgenes para el ejercicio de la ponderación de los intereses en el propósito de conjugar los propósitos de investigación, sanción y reparación de graves violaciones a los derechos humanos, de un lado, con los de reconciliación nacional y salida negociada de un conflicto armado no internacional, por el otro. No hay solución universalmente aplicable a los dilemas que plantea esa tensión, pues ella depende de cada contexto aunque sí 
Con respecto a los casos más complejos - es decir, la responsabilidad de los mandos a cargo de las acciones ilícitas que están comprometidos en crímenes que puedan ser calificados como crímenes de guerra o crímenes de lesa humanidad-, no es factible una medida de amnistía ${ }^{40}$, sería la excepción a lo "posible" del artículo pro-amnistías citado con anterioridad. En efecto, tal como se ha visto, un sistema de armonización de principios exige que ninguno de los principios en conflicto se anule para garantizar la vigencia del principio oponente. Las amnistías totales tienen como efecto imposibilitar que opere el principio señalado, a saber, la obligación internacional de investigar y sancionar a los responsables de graves violaciones de derechos humanos. Este tipo de amnistías impide la reparación de las víctimas por completo; como no se alcanza la verdad sobre los hechos, no es posible alcanzar la satisfacción mediante la aplicación de una sanción penal y no se genera un mensaje de no repetición ${ }^{41}$.

En relación con las amnistías condicionadas, se formula una crítica fuerte por la selectividad que supone su implementa-

hay lineamientos a tener en cuenta" (Voto concurrente, juez Diego García Sayán, caso Masacres de El Mozote y lugares aledaños vs. El Salvador. Fondo, Reparaciones y Costas. Sentencia de 25 de octubre de 2012. Serie C No. 252, párr. 20).

40 La Corte Constitucional, en la sentencia C-007/2018, bloque temático D.3, analiza este tema y concluye la constitucionalidad de la restricción a la medida de amnistía en estos casos.

41 La Corte Constitucional, antes del Acuerdo de Paz de 2016, había advertido que es válida la renuncia a la persecución penal, siempre que no se trate de un beneficio incondicionado, que se excluyan las más graves violaciones de los derechos humanos y que existan suficientes garantías para las víctimas (C-579 de 2013). ción ${ }^{42}$. Se compartimos el hecho de que la selectividad siempre está presente en el sistema penal y ello trae aparejado riesgos evidentes de discrecionalidad y arbitrariedad. El punto relevante es que esta crítica que se formula al derecho penal ordinario no puede trasladarse de forma automática al derecho penal como respuesta a crímenes atroces. En el caso de las amnistías condicionadas, a diferencia de aquel de las graves violaciones de derechos humanos, la selectividad está más acotada: crímenes políticos y conexos en el marco del conflicto armado ${ }^{43}$. De ahí que no parezca la selectividad como intrínsecamente violatoria de derechos humanos en la medida en que se cumpla con los requisitos de legitimidad del proceso (verdad, reparación y garantías de no repetición) $)^{44}$.

Los otros aspectos relevantes que muestran relación con el trato diferenciado en

42 Sobre el principio de selectividad en los casos de justicia transicional, ver Bergsmo y Saffon (2011).

43 Se está cumpliendo con lo que piden Uprimny y Sánchez (2019) sobre racionalizar la acción del Estado conforme a los fundamentos de los acuerdos básicos del proceso de paz.

44 Este aspecto lo analiza la Corte Constitucional ampliamente en la C-007/2018, bloque temático B.8, y concluye que "[...] un beneficio como la renuncia a la persecución penal es una medida que impone una restricción a los derechos de las víctimas y, especialmente, a la obligación de investigar, juzgar y sancionar las graves violaciones de derechos humanos. Por lo tanto, como lo sostuvo la Sala en la sentencia C-579 de 2013, este beneficio sólo [sic| es admisible si no cobija las más intensas lesiones a la dignidad humana, y si viene acompañado de una maximización de los demás derechos de las víctimas. El beneficio no es constitucionalmente admisible si su entrega y conservación no se sujeta a la contribución efectiva a los derechos de las víctimas; esta contribución debe darse, tanto al recibir el beneficio, como de forma continua, especialmente, en el ámbito de la construcción de la verdad y la memoria histórica" (párr. 166). 
el cual se basa el Acuerdo de Paz de 2016 son las sanciones penales disminuidas y/o distintas a la prisión y el acceso a un sistema de justicia especial (JEP) ${ }^{45}$. En cuanto a las penas disminuidas, es posible sostener que para viabilizar la sanción penal en el marco de un proceso de pacificación, resulta idóneo establecer un mecanismo que permita buscar alternativas que se mantengan en el ámbito de la respuesta penal, pero que no necesariamente impliquen penas de cárcel ${ }^{46}$. La sanción penal, como se ha sostenido previamente, es la respuesta culturalmente pertinente frente a crímenes de esta envergadura. Sin una respuesta penal no se envía un mensaje proporcional con respecto a crímenes graves: no hay sanción adecuada al responsable y se genera una sensación de impunidad y tolerancia con el ilícito.

La sanción penal tiene aparejada un reproche moral proporcional a los crímenes cometidos. Sin esta respuesta, el derecho penal queda limitado a la más criticable de sus expresiones: los crímenes ordinarios. Si tiene algún sentido la respuesta penal, esta es precisamente, castigar los crímenes más graves de la convivencia

45 El Acuerdo de Paz de 2016 establece escalas de penas disminuidas con respecto a los crímenes ordinarios y un juzgamiento a través de un sistema de justicia especial (Justicia Especial para la Paz) que se conceptualiza como "jurisdicción especial que ejerce funciones judiciales de manera autónoma y preferente sobre los asuntos de su competencia, en especial respecto a conductas consideradas graves infracciones al Derecho Internacional Humanitario o graves violaciones de los Derechos Humanos. Entrara[ en vigor en los términos establecidos en el Acuerdo Final. Se aplicará únicamente a conductas cometidas con anterioridad a su entrada en vigor" (Acuerdo de Paz, N. ${ }^{\circ}$ 9).

46 Sobre este tema, ver Corte Constitucional C-007/2018, bloque temático B.8, párrs. 155-166. social. Empero, esto no implica necesariamente que la sanción penal deba tener como consecuencia el aprisionamiento de los responsables. Nada en el sistema de derechos humanos permitiría sostener que la sanción a graves crímenes tiene que tener aparejada obligatoriamente una sanción de cárcel.

En el Estatuto de Roma, que solo contempla sanciones carcelarias (art 77), se deja explícitamente establecido que este tipo de penas contempladas en el Estatuto no impide que a nivel interno se decidan otro tipo de sanciones (art. 80). En esta misma línea se ha pronunciado la Corte Interamericana, que señaló que para cumplir con la Convención hay un solo elemento relevante: que la pena debe ser proporcional al delito cometido (Corte IDH. Caso de la Masacre de la Rochela vs. Colombia. Fondo, Reparaciones y Costas. Sentencia de 11 de mayo de 2007. Serie C No. 163, párr. 196; Corte IDH. Caso Manuel Cepeda Vargas vs. Colombia. Excepciones Preliminares, Fondo, Reparaciones y Costas. Sentencia de 26 de mayo de 2010. Serie C No. 213, párr. 150). En este sentido, es legítimo para una sociedad en un proceso de pacificación que debata sobre formas alternativas de sanción penal que, por una parte, sean una sanción efectiva y no ilusoria, pero que a la vez, le den viabilidad al proceso de paz. De ahí que se consagrara expresamente que las sanciones penales no alcanzarían los derechos políticos ${ }^{47}$.

${ }_{47}$ El Acuerdo de Paz dispone que: "La imposición de cualquier sanción en el SIVJRNR no inhabilitará para la participación política ni limitará el ejercicio de ningún derecho, activo o pasivo, de participación política, para lo cual las partes acordarán las reformas constitucionales 
La solución propuesta en el marco del Acuerdo de Paz permite conocer los hechos completos (verdad), aplicar las penas (satisfacción y garantía de no repetición) y luego pensar en medidas de clemencia (sanción disminuida). Asimismo, se aborda de manera satisfactoria el tema de la impunidad, ya que la idea de medidas de clemencia es distinta a aquella de impunidad vía las amnistías, puesto que sí hay una sanción penal, solo que matizada. Eso permite darle sentido a la pena en una sociedad democrática (Neumann, 2018) ${ }^{48}$.

Finalmente, el otro tema es aquel del juzgamiento a través de un sistema penal diferenciado ${ }^{49}$. En la medida en que dicho sistema garantice el cumplimiento de los objetivos del enjuiciamiento penal ${ }^{50}$ (verdad de los hechos, reparación de las víctimas y garantías de no repetición ${ }^{51}$ ) y en que a la vez garantice adecuadamente los derechos de los imputados, ${ }^{52}$

pertinentes" (N. ${ }^{\circ}$ 36). La Corte Constitucional estableció previamente la constitucionalidad de la vigencia de este derecho, pese a las sanciones penales en C-577/2014.

48 Ya en 2014, previo al Acuerdo de Paz, la Corte Constitucional había señalado que en Estado Social de Derecho, el instrumento penal en el marco de una situación excepcional, como el proceso de pacificación, debía tender a la reconciliación y la reconstrucción política y reparación de los lazos sociales rotos (C-577/2014, sección 5.2).

49 Acuerdo de Paz, N. ${ }^{\circ} 32$.

50 Para el Acuerdo de Paz, las sanciones tendrán "como finalidad esencial satisfacer los derechos de las víctimas y consolidar la paz. Deberán tener la mayor función restaurativa y reparadora del daño causado, siempre en relación con el grado de reconocimiento de verdad y responsabilidad que se haga ante el componente de Justicia del SIVJRNR mediante declaraciones individuales o colectivas" ( $\left.N^{\circ} 60\right)$.

51 Alude a: Corte Constitucional C-007/2018, particularmente párrafos 387, 395 y 671 (este último referido a la reparación integral).

52 El Acuerdo de Paz consagra que "Todas las actuaciones y tenga un control constitucional ${ }^{53}$, da las garantías necesarias de legitimidad para todos los intervinientes y, simultáneamente, viabiliza el proceso de paz al establecer un sistema de justicia expedito y transparente para enfrentar las formas particulares de criminalidad que se dan en el marco de un conflicto armado, de características muy distintas a la de la delincuencia ordinaria (Reyes, 2018) ${ }^{54}$.

Así las cosas, se está frente a un sistema especial que busca beneficiar a quienes participen de él, sin por ello dejar de resguardando los derechos de las víctimas, por lo que no concurren elementos para determinar su incompatibilidad con las garantías de un debido proceso conforme al art. 8 de la $\mathrm{CADH}$.

\section{CONCLUSIONES}

En el presente escrito se ha sustentado la hipótesis propuesta, a saber, que el proceso de paz colombiano ratifica que la justicia transicional -incluso al ser aplicada a procesos de pacificación

en el componente de justicia, de conformidad con las reglas aplicables a la Jurisdicción Especial para la Paz, respetarán los derechos fundamentales del debido proceso" (N. ${ }^{\circ}$ 14). Por su parte, el art. 21 de la Ley Estatutaria de la Administración de Justicia en la Jurisdicción Especial para la Paz, garantiza el Debido Proceso para quienes sean juzgados por dicho sistema judicial especial. Esta norma fue declarada constitucional por la Corte Constitucional en la sentencia C-080/2018, del 15 de agosto del 2018.

53 La Corte Constitucional ha señalado que las tutelas dictadas en el marco de la JEP pueden ser objeto de revisión constitucional por parte de la Corte (C-008/2018, párrs. 642-649). En el mismo sentido, ver C-674/2017.

54 Este es un aspecto que ya había sido recalcado por la Corte Constitucional en C-577/2014 cuando analizó el tema de los derechos políticos en el marco de la reforma constitucional del art. 66, particularmente, en la sección 5.1 . 
como el colombiano-, encuentra límites en el DIDH con relación a tres aspectos en específico: a) no proceden amnistías o indultos para violaciones graves de los derechos humanos; b) sí es posible implementar medidas de impunidad condicionadas al deber de reparar a las víctimas; y c) sí proceden medidas penales que impliquen un trato diferenciado de quienes han incurrido en violaciones de derechos humanos en el ámbito del conflicto armado, siempre y cuando estas mantengan ciertos derechos mínimos con respecto a la reparación de las víctimas.

Con ello, se consolida la tesis de que los procesos de justicia transicional, incluida su faceta de pacificación, no abren espacios de excepcionalidad a las obligaciones internacionales sobre derechos humanos, sino que establecen condiciones particulares para su implementación.

Se analizó la obligación del Estado de investigar y sancionar los crímenes graves de derechos humanos ocurridos en el conflicto armado, lo que incluye la respuesta penal. Esta respuesta es la que de mejor manera cumple con los objetivos de justicia de todo proceso de pacificación que quiera fundamentarse en el respeto de los derechos humanos.

La respuesta penal puede y debe ser matizada a la luz del contexto en que se da el proceso colombiano, un conflicto armado aún en desarrollo. Por ello, la respuesta penal debe reservarse para aquellos casos más graves, respecto a los cuales no puede haber perdón, pero sí medidas de clemencia.
El Acuerdo de Paz de 2016 y el sólido desarrollo jusrisprudencial de la Corte Constitucional para darle sustento constitucional e internacional, da cuenta de una permanente búsqueda de armonización entre la búsqueda de la paz y el respeto de las obligaciones del Estado en materia de derechos humanos, en particular, de la obligación de reparación a las víctimas del conflicto acorde a los parámetros internacionales y, en especial, los interamericanos.

La forma en quela sociedad colombiana ha armonizado el respeto de los derechos humanos y la viabilidad del proceso de pacificación marcan la solidez de su proceso democrático y la profundidad de la paz obtenida, así como los estándares internacionales en materia de juzgamiento y sanción de los responsables de violaciones de derechos humanos.

\section{REFERENCIAS}

Alexy, R. (2002). Teoría de los derechos fundamentales. Madrid, España: Centro de Estudios Constitucionales.

Alexy, R. (2005). Teoría del Discurso y derechos constitucionales. Cátedra Ernesto Garzón Valdés 2004. Ciudad de México, México: Distribuciones Fontamara.

Asamblea General de las Naciones Unidas (2005). Principios y directrices básicos sobre el derecho de las víctimas de violaciones manifiestas de las normas internacionales de derechos humanos y de violaciones graves del derecho internacional humanitario a interponer recursos y obtener reparaciones. 60/147. Resolución aprobada por la Asamblea General el 16 de diciembre de 2005. Recuperado de https://www. ohchr.org/sp/professionalinterest/pages/ remedyandreparation.aspx 
Barbosa, G. (2016). Justificación de la Pena en la Justicia Transicional. En Justicia Transicional: retos teóricos (pp. 97-196). Bogotá, Colombia: Universidad Externado de Colombia.

Bergsmo, M., y Saffon, M.P., (2011). Enfrentando una fila de atrocidades pasadas. ¿Cómo seleccionar y priorizar casos de crímenes internacionales centrales?. En K. Ambos (Ed.), Selección y priorización como estrategia de persecución en los casos de crímenes internacionales. Un estudio comparado (pp.23-118). Bogotá, Colombia: ProFis-GIZ.

Boraine, A. (2000). A country unmasked. Southern Africa: Oxford University Press.

Bulygin, E. (2001). Procesos penales por violación de derechos humanos. En Seminario en Latinoamérica de Teoría Constitucional y Política, SELA 2001 (pp.343-349). Buenos Aires, Argentina: Editores del Puerto s.r.l..

Comisión de Derecho Internacional (2017). Texto y título del proyecto de preámbulo, los proyectos de artículo y el proyecto de anexo aprobados provisionalmente por el Comité de Redacción en primera lectura, 26 de mayo de 2017 (A) CN.4/L.892).

Comisión de Derechos Humanos (2000). Informe sobre $\mathrm{El}$ derecho de restitución, indemnización y rehabilitación de las víctimas de violaciones graves de los derechos humanos y las libertades fundamentales, presentado por M. C. Bassiouni (2000) en virtud de la resolución 1999/33, E/ CN.4/2000/62, 18 de enero de 2000.

Comisión Interamericana de Derechos Humanos (CIDH) (2013). Verdad, Justicia y Reparación: Cuarto informe sobre la situación de derechos humanos en Colombia, OEA/Ser.L/V/II. Doc.49/13, 31 diciembre de 2013. Recuperado de http://www.oas.org/es/cidh/docs/pdfs/ Justicia-Verdad-Reparacion-es.pdf

Comité de Derechos Humanos (1989). Observación General 18. Discriminación. Sesión 37ª. HRI/ GEN/1/Rev.9 (Vol.I)
Consejo de Derechos Humanos de Naciones Unidas (2014a). Informe del Relator Especial sobre la promoción de la verdad, la justicia, la reparación y las garantías de no repetición, Pablo de Greiff. Informe 27 de agosto del 2014, A/HRC/27/56.

Consejo de Derechos Humanos de Naciones Unidas (2014b). Informe del Relator Especial sobre la promoción de la verdad, la justicia, la reparación y las garantías de no repetición, Pablo de Greiff. Misión a España. Informe 22 de julio del 2014. (A/HRC/27/56/Add.1).

Corte Constitucional de Colombia (2013). C-579/2013, de 28 de agosto de 2013, MP Jorge Pretelt Chaljub.

Corte Constitucional de Colombia (2014). C-577/2014, de 06 de agosto de 2014, MP Martha Sáchica Méndez.

Corte Constitucional de Colombia (2015). C-694/2015, de 11 de noviembre de 2015, MP Alberto Rojas Ríos.

Corte Constitucional de Colombia (2018). C-007/2018, de 01 de marzo de 2018, MP Diana Fajardo Rivera.

Corte Constitucional de Colombia (2018). C-080/2018, de 15 de agosto de 2018, MP Antonio Lizarazo Ocampo.

Corte IDH. Caso Velásquez Rodríguez vs. Honduras. Fondo. Sentencia de 29 de julio de 1988. Serie C No. 4

Corte IDH. Caso de la "Panel Blanca" (Paniagua Morales y otros) vs. Guatemala. Reparaciones y Costas. Sentencia de 25 de mayo de 2001. Serie C No. 76

Corte IDH. Caso 19 Comerciantes vs. Colombia. Fondo, Reparaciones y Costas. Sentencia de 5 de julio de 2004. Serie C No. 109

Corte IDH. Caso Masacre Plan de Sánchez vs. Guatemala. Reparaciones. Sentencia de 19 de noviembre 2004. Serie C No. 116 
Corte IDH. Caso Carpio Nicolle y otros vs. Guatemala. Fondo, Reparaciones y Costas. Sentencia de 22 de noviembre 2004. Serie C No. 117

Corte IDH. Caso de la Comunidad Moiwana vs. Surinam. Excepciones Preliminares, Fondo, Reparaciones y Costas. Sentencia 15 de junio de 2005. Serie C No. 124

Corte IDH. Caso de la "Masacre de Mapiripán" vs. Colombia. Sentencia de 15 de septiembre de 2005. Serie C No. 134

Corte IDH. Caso de la Masacre de Pueblo Bello vs. Colombia. Fondo, Reparaciones y Costas. Sentencia de 31 de enero de 2006. Serie C No. 140

Corte IDH. Caso Goiburú y otros vs. Paraguay. Fondo, Reparaciones y Costas. Sentencia de 22 de septiembre de 2006. Serie C No. 153

Corte IDH. Caso Almonacid Arellano y otros vs. Chile. Excepciones Preliminares, Fondo, Reparaciones y Costas. Sentencia de 26 de septiembre de 2006. Serie C No. 154

Corte IDH. Caso de la Masacre de la Rochela vs. Colombia. Fondo, Reparaciones y Costas. Sentencia de 11 de de mayo de 2007. Serie C No. 163

Corte IDH. Caso Kimel vs. Argentina. Fondo, Reparaciones y Costas. Sentencia de 2 de mayo de 2008 Serie C No. 177

Corte IDH. Caso Manuel Cepeda Vargas vs. Colombia. Excepciones Preliminares, Fondo, Reparaciones y Costas. Sentencia de 26 de mayo de 2010. Serie C No. 213

Corte IDH. Caso Gomes Lund y otros (Guerrilha do Araguaia) vs. Brasil. Excepciones Preliminares, Fondo, Reparaciones y Costas. Sentencia de 24 de noviembre de 2010 Serie C No. 219

Corte IDH. Caso Gelman vs. Uruguay. Fondo y Reparaciones. Sentencia de 24 de febrero de 2011 Serie C No. 221
Corte IDH. Caso Vera Vera y otra vs. Ecuador. Excepción Preliminar, Fondo, Reparaciones y Costas. Sentencia de 19 de mayo de 2011. Serie C No. 226

Corte IDH. Caso Masacres de El Mozote y lugares aledaños vs. El Salvador. Fondo, Reparaciones y Costas. Sentencia de 25 de octubre de 2012. Serie C No. 252

Corte IDH. Caso Rodríguez Vera y otros (Desaparecidos del Palacio de Justicia) vs. Colombia. Excepciones Preliminares, Fondo, Reparaciones y Costas. Sentencia de 14 de noviembre de 2014. Serie C No. 287

Corte Penal Internacional (1998, julio 17). Estatuto de Roma. Recuperado de http://www.hchr. org.co/documentoseinformes/documentos/ html/pactos/estatuto _ roma_corte _ penal_internacional.html

De Greiff, P. (2006). "Justice and Reparations". En The Handbook of Reparations, UK: Oxford University Press, pp. 451-477.

Hayner, P. (2010). Unspeakable truths: Transitional justice and the challenge of truth commissions. New York, USA y London, UK: Routledge.

Knust, K. (2018). Pena, pena atenuada e impunidad. El papel del derecho penal en sociedades postconflicto. En ¿Es injusta la Justicia Transicional? (pp. 135-190). Bogotá, Colombia: Universidad Externado de Colombia.

Kritz, N. J. (1995), Transitional Justice. Washington, D.C.: United States Institute of Peace Press.

Mañalich, J. P. (2010). Terror, Pena y Amnistía. Santiago, Chile: Editorial Flandes Indiano.

Miranda, B. (2016, octubre 3). Las razones por las que el "No" se impuso en el plebiscito en Colombia. BBC Mundo. Recuperado de https://www.bbc.com/mundo/ noticias-america-latina-37537629 
Nash, C. (2009). Las reparaciones en la jurisprudencia de la Corte Interamericana de Derechos Humanos (1988-2007) ( $2^{\mathrm{a}}$ ed.). Santiago, Chile: Centro de Derechos Humanos.

Nash, C. (2010). Caso Goiburu vs. Paraguay. La justicia transicional en el banquillo de la Corte Interamericana. En El Sistema Interamericano de Derechos Humanos en Acción. Aciertos y desafios (pp. 211-226). Ciudad de México, México: Editorial Porrúa.

Nash, C. (2013). Sistema Interamericano de Dereitos Humanos e Justicia Transicional. Revisando o disenho predominante. En J. C. C. Moreira da Silva. (Ed.), Justica de Transicao nas Americas (pp. 315-341). Belo Horizonte, Brasil: Editora Forum.

Neumann, U. (2018). Problemas jurídico-penales fundamentales de la justicia de transición. En Y. Reyes (Ed.), ¿Es injusta la Justicia Transicional? (pp. 99-134). Bogotá, Colombia: Universidad Externado de Colombia.

Nino, C. (1991). The duty to punish past abuses of human rights put into context: the case of Argentina. Yale Law Journal, 100(8), 2619-2640.

Oficina del Alto Comisionado para los Derechos Humanos (OACDH) (2009). Instrumentos del Estado de Derecho para Sociedades que han Salido de un Conflicto. Amnistías. Oficina del Alto Comisionado de Derechos Humanos. HR/ PUB/09/1.

Oficina del Alto Comisionado para La Paz (OACP). (2016, noviembre 14). Acuerdo final para la terminación del conflicto y la construcción de una paz estable y duradera. Bogotá: OACP. Recuperado de http://www.altocomisionadoparalapaz. gov.co/procesos-y-conversaciones/ Documentos\%20compartidos/24-11-2016 NuevoAcuerdoFinal.pdf

Orentlicher, D. (1991). Settling Accounts: The Duty to Prosecute Human Rights Violations of a Prior Regime. The Yale Law Journal, 100(8), 2537-2615.
Orozco, I. (2009). Justicia transicional en tiempos de deber de memoria, Bogotá, Colombia: Temis, Universidad de Los Andes.

Prieto Sanchís, L. (2003). Justicia constitucional $y$ derechos fundamentales. Madrid, España: Editorial Trotta.

Ralws, J. (1971). Teoría de la Justicia. Ciudad de México, México: Fondo de Cultura Económica, México.

Reyes, Y. (2018). ¿Es injusta la justicia transicional? A manera de estudio preliminar. En Y. Reyes. (Ed.), ¿Es injusta la Justicia Transicional? (pp. 13-34). Bogotá: Colombia. Universidad Externado de Colombia.

Robins, S. (2017). Failing Victims? The Limits of Transitional Justice in Addressing the Needs of Victims of Violations. Human Rights and International Legal Discourse, 11(1), 41-58.

Sikkink, K. (2013). The Justice Cascade: How Human Rights Prosecutions Are Changing World Politics. New York, USA: W. W. Norton \& Company, Inc.

Teitel, R. (2000). Transitional justice. New York, USA: Oxford University Press.

Teitel, R. (2016). Justicia Transicional y el Proceso de Paz en Colombia. En Justicia Transicional: retos teóricos (pp. 283-320). Bogotá, Colombia. Universidad Externado de Colombia.

Tomuschat, C. (1999). Individual reparations claims in instances of grave human rights violations: the position under General International Law. En A. Randelzhofer y C. Tomuschat. (Eds.), State responsibility and the individual. Reparation in instances of grave violations of human rights (pp. 1-25). The Hague, Netherlands: Kluwer International Law.

Uprimny, R. (Ed.) (2006). ¿justicia transicional sin transición? Verdad, justicia y reparación para Colombia. Bogotá, Colombia: DeJusticia. 
Uprimny, R. y Sánchez, C. (2019). "The challenges of negotiated transitions in the era of international criminal law". En The duty to investigate, prosecute and punish the most serious crimes (pp. 18-71). Bogotá, Colombia: Colección DeJusticia.

Varney, H. (2013, enero 14). Ignorando sus demandas de justicia, Sudáfrica fracasa ante las víctimas del apartheid (J. Cuellar trad.) ICTJ.
Recuperado de https://www.ictj.org/es/news/ ignorando-sus-demandas-de-justicia-sudafrica-fracasa-ante-las-victimas-del-apartheid

Zalaquett, J. (1999). La reconstrucción de la unidad nacional y el legado de violaciones de los derechos humanos. Revista Perspectivas, 2(número especial). 385-405. 